\title{
Vaginal leiomyoma: medical imaging and diagnosis in a resource low tertiary hospital: case report
}

\author{
Thomas Obinchemti Egbe ${ }^{1,2^{*}}$ (D), Fidelia Mbi Kobenge ${ }^{2}$, Junette Arlette Mbengono Metogo 3,4 , \\ Emmanuella Manka'a Wankie ${ }^{5}$, Paul N. Tolefac $^{6}$ and Eugene Belley-Priso ${ }^{6}$
}

\begin{abstract}
Background: In the literature under review there are about 300 reported cases of vaginal leiomyomas with none from Cameroon. We report a case of vaginal leiomyoma and highlight the diagnostic challenges faced at the Douala Referral Hospital (DRH), Cameroon.

Case presentation: A 36-year-old G3P3002 sexually active Cameroonian married woman reported dysuria, dyspareunia, cessation of sexual intercourse and offensive smelling vaginal discharge for 6 months and a 3-year history of a vaginal tumour; she was misdiagnosed despite ultrasonography and magnetic resonance imaging (MRI) but was corrected by an experienced radiologist. She underwent first look laparoscopy, surgical excision of the tumour through the vagina and histopathology analysis that confirmed leiomyoma.

Conclusion: Posterior location of vaginal leiomyomas found in this case is a rare occurrence. The diagnosis is based on careful examination and preoperative imaging (ultrasonography and MRI). However, the definitive diagnosis is usually made intra-operatively. We combined laparoscopic exploration of the internal genital organs and per vaginal excision of the vaginal leiomyoma. Thus, we recommend frozen section biopsy to exclude leiomyosarcoma.
\end{abstract}

Keywords: Vaginal leiomyoma, Misdiagnosis, Laparoscopy, Magnetic resonance imaging, And ultrasonography

\section{Background}

Vaginal leiomyomas are rare benign tumours with only about 300 reported cases in medical literature [1]. To the best of our knowledge, there has been no case of vaginal leiomyoma reported in the medical literature from sub-Saharan Africa, and Cameroon in particular. These tumours usually arise from the anterior vaginal wall and, depending on the size and site, may cause varied clinical presentations such as dyspareunia, pain, or dysuria [2]. Vaginal leiomyomas sometimes occur concurrently with leiomyomas elsewhere in the body [3]. The clinical diagnosis of vaginal leiomyoma requires a high index of suspicion because the tumour could easily be mistaken for a cystocele, urethrocele, Skene duct abscess, Gartner duct cysts, urethral diverticulum, vaginal cysts, Bartholin

\footnotetext{
*Correspondence: toegbe@gmail.com; obinchemti@yahoo.com

${ }^{1}$ Faculty of Health Sciences, University of Buea, P.O. Box 63, Buea, Cameroon ${ }^{2}$ Department of Obstetrics and Gynecology, Douala Referral Hospital, P.O. Box 4856, Douala, Cameroon

Full list of author information is available at the end of the article
}

gland cysts, or vaginal malignancy $[4,5]$. The diagnosis is usually confirmed by histopathology.

We are reporting the case of a vaginal leiomyoma that we treated with first look laparoscopy and surgical excision through the vaginal route at the Douala Referral Hospital (DRH), Cameroon.

\section{Case presentation}

A 36-year-old G3P3002 sexually active Cameroonian married woman came to our department complaining of dysuria, dyspareunia, cessation of sexual intercourse and offensive foul-smelling vaginal discharge for a period of 6 months. She had noticed a growth bearing down on her vagina 3 years earlier and the growth rapidly increased in size in the last 6 months. On physical examination, she looked well; her blood pressure was $130 / 80$ $\mathrm{mmHg}$, pulse 84 beats $/ \mathrm{min}$. and temperature of $37.4{ }^{\circ} \mathrm{C}$. She had a non-tender tumour that was rubbery in

(c) The Author(s). 2020 Open Access This article is distributed under the terms of the Creative Commons Attribution 4.0 International License (http://creativecommons.org/licenses/by/4.0/), which permits unrestricted use, distribution, and reproduction in any medium, provided you give appropriate credit to the original author(s) and the source, provide a link to the Creative Commons license, and indicate if changes were made. The Creative Commons Public Domain Dedication waiver (http://creativecommons.org/publicdomain/zero/1.0/) applies to the data made available in this article, unless otherwise stated. 
consistency and occluding the vagina thereby impeding access to the uterine cervix. On digital rectal examination, the tumour was impinging on and compressing both the bladder and the rectum (Fig. 1); allowing for micturition only in the erect position. Blood levels of tumour markers showed the following: CA 125; $12 \mathrm{IU} /$ $\mathrm{mL}$ (normal value $<35 \mathrm{IU} / \mathrm{mL}$ ), CA 19.9; $5.4 \mathrm{IU} / \mathrm{mL}$ (normal value $<37 \mathrm{IU} / \mathrm{mL}$ ) and CA 15.3; $1.2 \mathrm{IU} / \mathrm{mL}$ (normal value $<31.3 \mathrm{IU} / \mathrm{mL}$ ). Furthermore, hemoglobin level was $10.8 \mathrm{~g} / \mathrm{dL}$, hematocrit level 32.5\%; aspartate aminotransferase (AST) 18.4 IU/L (normal value $<46 \mathrm{IU} / \mathrm{L}$ ), alanine aminotransferase (ALT); $10.3 \mathrm{IU} / \mathrm{L}$ (normal value $<49$ $\mathrm{IU} / \mathrm{L}$ ), blood urea nitrogen (BUN); $0.25 \mathrm{~g} / \mathrm{L}$ (normal value; 0.15 to $0.45 \mathrm{~g} / \mathrm{L}$ ), and creatinine level $9.5 \mathrm{mg} / \mathrm{L}$ (normal value; 6 to $13 \mathrm{mg} / \mathrm{L}$ ). Besides, immunohistochemistry was not accessible in the DRH during the period of study therefore we could not measure the LDH levels. An abdominal ultrasonography showed a 60 $\mathrm{mm} \times 40 \mathrm{~mm}$ hypoechogenic tumour in the upper part of the vagina and pelvis. Magnetic resonance imaging (MRI) of the abdomen and pelvis had earlier misdiagnosed the tumour; right posterior pelvic peritoneal tumour measuring $(137 \times 73 \times 118 \mathrm{~mm})$. However, a reexamination of the MRI images by an experienced radiologist correctly diagnosed a vaginal tumour $(102.7 \times$ $175.8 \mathrm{~mm}$ ) bulging through the posterior fornix and pushing up the pouch of Douglas and compressing the bladder and rectum, which is suggestive of vaginal leiomyoma (Fig. 2 and Fig. 3). The tumour was projecting

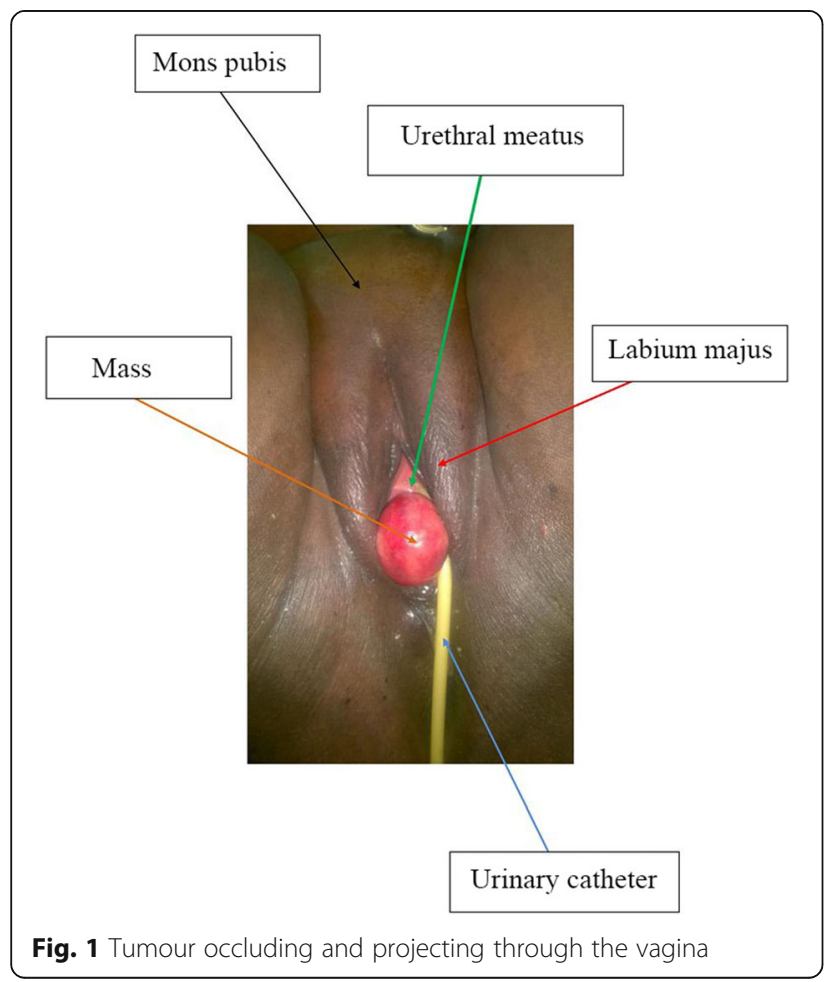

through the vulva. A biopsy and histopathology of the visible vaginal tumour confirmed leiomyoma. At first look laparoscopy, the uterus and adnexa were normal and both deviated to the right side of the pelvis. We excised the leiomyoma through the vaginal route by sharp and blunt dissection. We removed a whorled whitish lobular vaginal fibroid $(131.4 \times 147.7 \mathrm{~mm})$ occupying the rectovaginal space. The fourchette provided attachment for the vaginal leiomyoma (Fig. 4). Vaginal closure was in two layers and blood loss was minimal. The uterine cervix was microscopically normal (Fig. 5), and postoperative histopathology confirmed vaginal leiomyoma.

\section{Discussion and conclusion}

Leiomyomas are benign tumours of the female genital tract common among African-American and black women of reproductive age [6-8]. These tumours are common in the uterus and to some extent, in the cervix, the round ligament, uterosacral ligament, ovary, and inguinal canal, respectively [1].

\section{Prevalence of vaginal leiomyoma}

Leiomyomas of the vagina are rare and there are 300 reported cases in the medical literature we reviewed $[1,3]$. Vaginal leiomyomas are common in women between 35 to 50 years and more common among Caucasian women [3]. Vaginal leiomyomas are rare in most sub-Saharan African countries, as opposed to uterine leiomyomas. The reason for this difference is attributed to misdiagnosis, failure to seek medical attention and lack of correct reporting.

\section{Diagnosis of vaginal leiomyoma}

These tumours usually occur as a single, wellcircumscribed mass arising from the midline anterior wall, and less commonly from the anterior and lateral walls [9]. In our case, the tumour was not well circumscribed as described in the literature and was located in the posterior wall (recto-vaginal space), thereby decreasing the clinical likelihood of suspicion. Vaginal tumours are usually asymptomatic but may occasionally present symptoms ranging from lower abdominal pain, low back pain, vaginal bleeding, dyspareunia, urinary symptoms like frequency, dysuria or other features of vagina or urinary obstruction $[2,10]$. Preoperative imaging and careful examination may help rule out a malignancy. However, this was not the case with the index case that underwent biopsy because tumour was accessible. Besides, others have reported abnormally high levels of CA 125, CA 19.9 and CA 15.3 in $19.7 \%, 6.6 \%$ and $5.1 \%$ of patients, respectively [11] but we did not find similar results in the index case. Furthermore, elevated levels of lactate dehydrogenase LDH-A and LDH-D were reported in patients with uterine leiomyosarcoma compared with those with uterine leiomyomas [12]. 


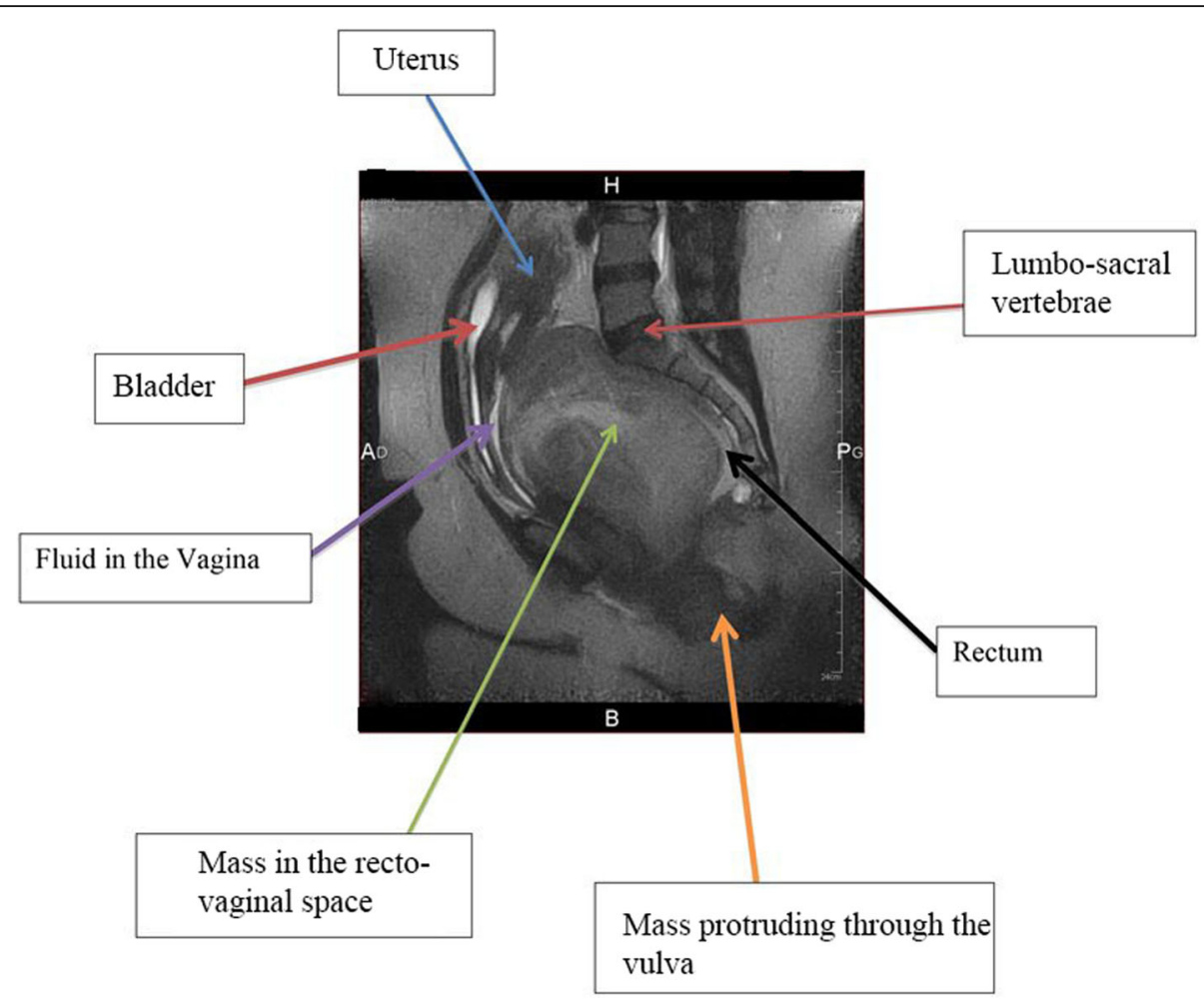

Fig. 2 Magnetic Resonance Image (longitudinal view) of the pelvis and perineum showing pelvic mass, and fluid collection in the vagina. The uterus is deviated by the mass with secretions flowing through the cervix. The mass compresses the bladder anteriorly and the rectum posteriorly

In addition, other studies have suggested that, the assessment of LDH isoenzymes may be relevant in the preoperative diagnosis of uterine sarcoma [13]. However, $\mathrm{LDH}$ assessment was not accessible to the index case because of lack of facilities to carry out immunohistochemistry at the time of study. We used ultrasonography and MRI in diagnosing vaginal tumour. At the $\mathrm{DRH}$, magnetic resonance imaging (MRI) is meant for suspected malignancies because it is not accessible to most patients due to the cost (about \$250). In MRI, the tumour appears as a well-demarcated solid mass of low signal intensity in T1 and T2 weighted images with homogenous contrast enhancement while leiomyosarcomas and other vaginal malignancies show characteristic high T2 signal intensity with irregular and heterogeneous areas of necrosis or haemorrhage $[9,14,15]$. The use of MRI is especially useful when fibroids are growing rapidly, have poor delineation on ultrasound and when there is suspicion of malignancy [16]. MRI is accurate in diagnosing a leiomyoma with a sensitivity of $88-93 \%$ and a specificity of $66-91 \%$ [6].

There is a reported case of necrotizing ruptured leiomyoma mimicking a malignant neoplasm that was clarified by MRI. The mass was $70 \mathrm{~mm} \times 50 \mathrm{~mm}$ at the distal end of the left anterior aspect of the vagina displacing the urethra anteriorly. It has low signal intensity on T1- weighted image, high signal intensity on T2 weighted image and irregular enhancement on post-contrastenhanced image as if it were a malignant tumour [4].

There is an estimated 2 to $5 \%$ error margin in radiological examinations in the medical literature and this may increase to $40 \%$ in emergencies. We attribute these errors to complacency, poor communication, staff shortage, heavy workloads, a dearth of earlier reports for comparison, and unavailability of trained radiologists [17-20]. In the present context, there is no study in the Department of Radiology of the DRH to estimate radiologic accuracy. There are an estimated 140 radiology examinations per day in the Radiology Department of the DRH. Assuming a 2 to $5 \%$ margin of error [16-18] in radiologic diagnosis as reported previously, a misdiagnosis in diagnostic radiology may occur several times per day at the DRH.

\section{Management of Vaginal Leiomyomas}

Surgical excision through the vaginal route has been the traditional approach for vaginal tumours but the abdominoperineal route is necessary for huge tumours [3, 19]. For the index case, we combined laparoscopic exploration of the abdominal cavity (internal genital organs) and per vaginal excision of the vaginal leiomyoma. 


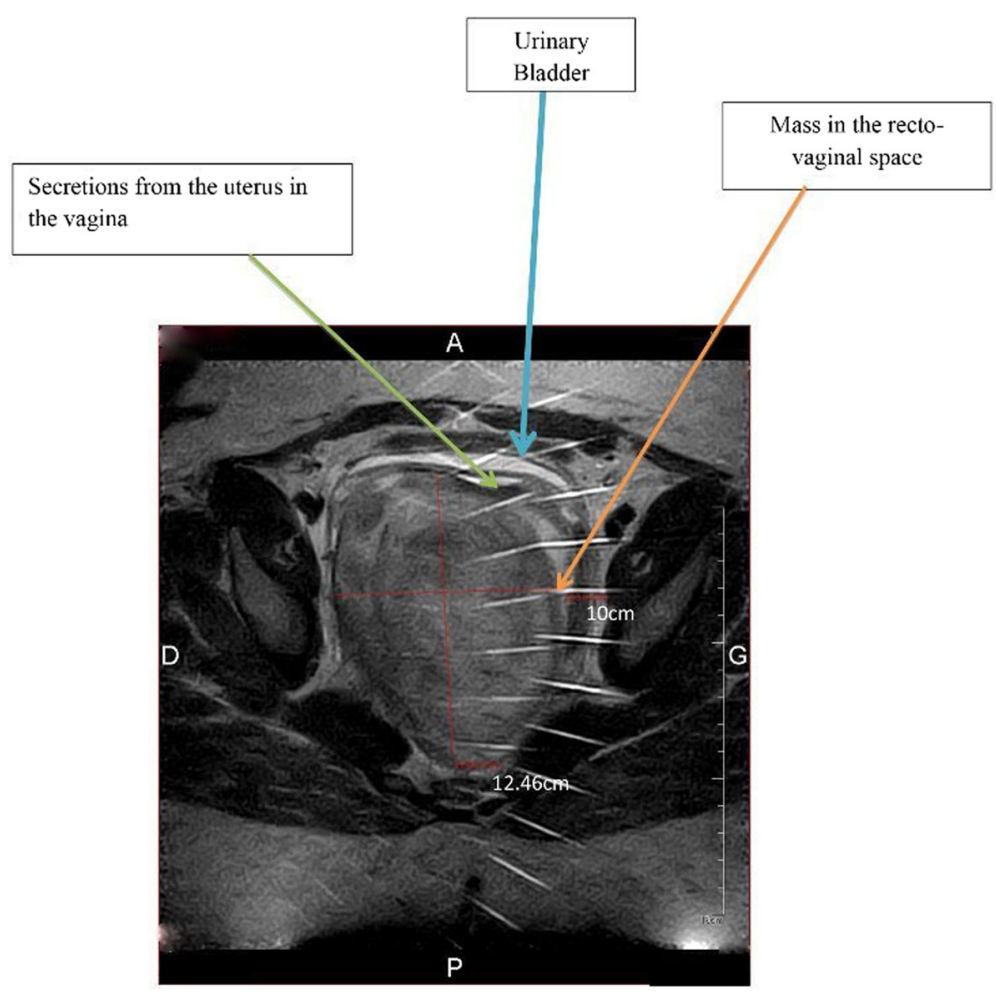

Fig. 3 Magnetic resonance image (Cross-sectional view) of the pelvis and perineum. The uterus is not visualized in this section. The mass is seen with free fluid in the vagina

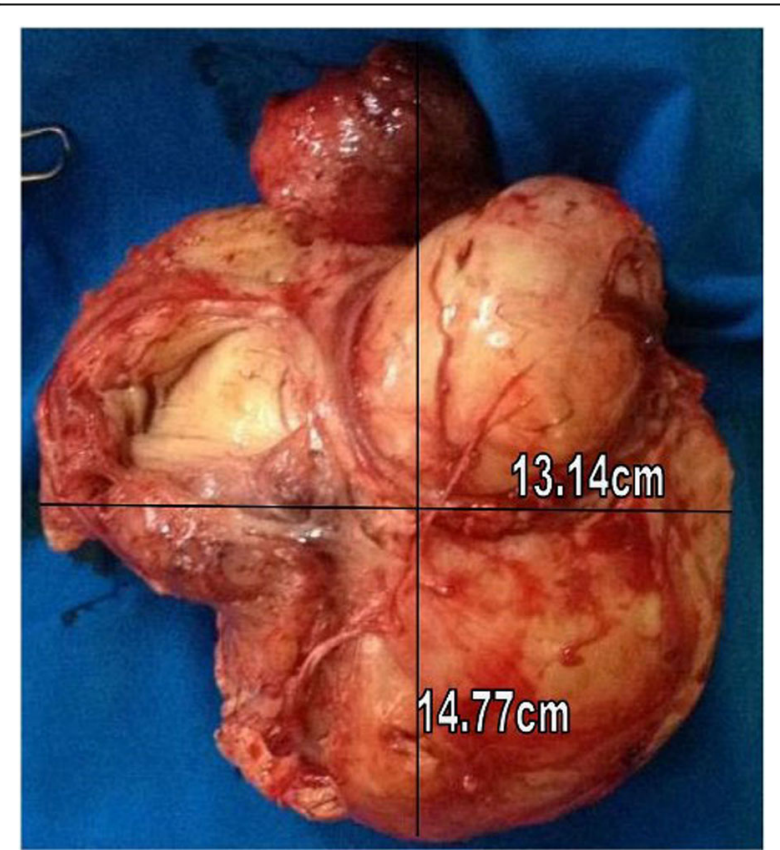

Fig. 4 Vaginal tumour removed having whorled yellowish-white appearance characteristic of leiomyoma and measuring $13.14 \mathrm{~cm} \times$ $14.77 \mathrm{~cm}$
Some studies have reported the assessment of LDH isoenzymes levels by immunohistochemistry to differentiate between leiomyoma and leiomyosarcoma. However, because of the lack of immunohistochemistry facility and risk of misdiagnosis during MRI, frozen biopsy may be important to differentiate leiomyosarcoma from leiomyoma in our setting. Besides, other studies have reported that the overall accuracy of frozen section to determine the status of malignancy was $93.3 \%$ in patients with ovarian tumours [21]. Furthermore, another study have reported that Frozen section performed at the time of a total hysterectomy rendered the diagnosis of malignant mixed-müllerian tumour [22]. There are reports of laparoscopic ablation of a tumour with posterior colpotomy for the management of vaginal leiomyomas but this has not gained worldwide acceptance [23]. However, if vaginal leiomyoma is diagnosed before surgery, gonadotropin-releasing hormone analogues (GnRH-a) or selective progesterone receptor modulators (SPRM) to reduce tumour size or preoperative embolization to reduce intraoperative blood loss may be used [24]. Furthermore, there are reports of changes in sexuality and intimacy among patients after diagnosis and treatment of vaginal tumours [25]. This couple had also suspended sexual intercourse and therefore required psychological support. 


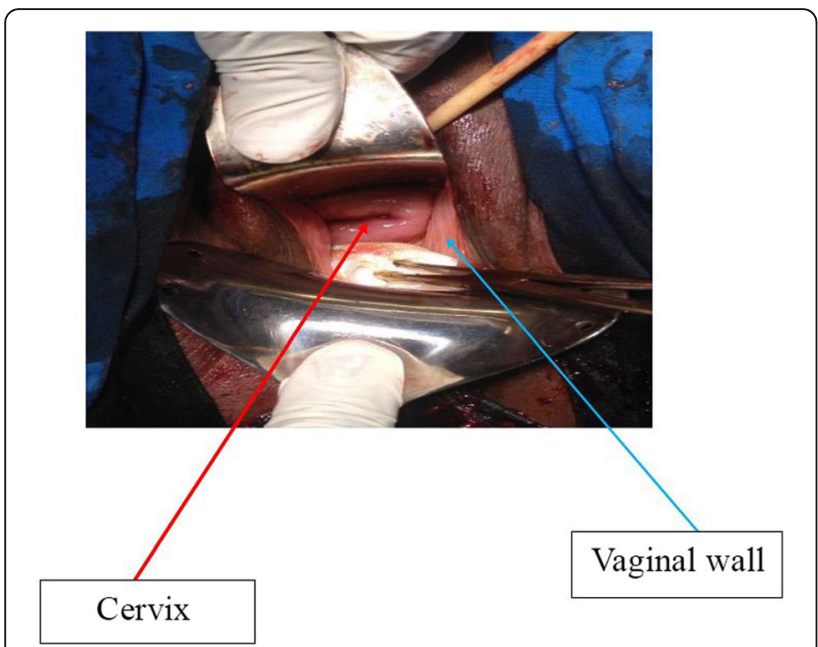

Fig. 5 Vagina after removal of tumour. The uterine cervix is macroscopically normal

\section{Limitations}

There is a reported correlation between estrogen (ER) and epidermal growth factor (EGFR) receptors and vaginal leiomyoma [22] but we did not have the facilities to do immunohistochemistry. The couple could not get psychological support because of a lack of staff to offer such services.

In conclusion, posterior location of vaginal leiomyomas found in this case is a rare occurence. The diagnosis is based on careful examination and preoperative imaging (ultrasonography and MRI). However, definitive diagnosis is usually made intra-operatively. We combined laparoscopic exploration of the internal genital organs and per vaginal excision of the vaginal leiomyoma. Thus, we recommend frozen section to exclude leiomyosarcoma.

\section{Abbreviations}

ALT: Alanine aminotransferase; AST: Aspartate aminotransferase; CA: Cancer antigen or carcinoma antigen; DRH: Douala Referral Hospital;

EGFR: Epidermal growth factor; ER: Estrogen receptor; GnRH-a: Gonadotropin releasing hormone analog; LDH: Lactate dehydrogenase; MRI: Magnetic resonance imaging; SPRM: Selective progesterone receptor modulator

\section{Acknowledgements}

We are grateful to the nurses and staff of the Douala Referral Hospital for their support during the management of the patient.

\section{Authors' contributions}

TOE, PNT contributed to the project development and manuscript writing/ editing. TOE, FMK, MMJA, EBP: were a part of the surgical team and alongside author EMW, contributed in the imaging studies and editing of the manuscript. All authors read and approved the final manuscript.

\section{Funding}

None.

\section{Availability of data and materials}

Not applicable.

Ethics approval and consent to participate Not applicable.

\section{Consent for publication}

Written informed consent was obtained from the patient for publication of this case report and any accompanying images. A copy of the written consent is available for review by the editor-in-chief of this journal.

\section{Competing interests}

The authors declare that they have no competing interests.

\section{Author details}

${ }^{1}$ Faculty of Health Sciences, University of Buea, P.O. Box 63, Buea, Cameroon. ${ }^{2}$ Department of Obstetrics and Gynecology, Douala Referral Hospital, P.O. Box 4856, Douala, Cameroon. ${ }^{3}$ Faculty of Medicine and Pharmaceutical Sciences, University of Douala, Douala, Cameroon. ${ }^{4}$ Department of Anesthesiology and Reanimation, Douala Referral Hospital, Douala, Cameroon. ${ }^{5}$ Department of Radiology, Douala Referral Hospital, Douala, Cameroon. ${ }^{6}$ Faculty of Medicine and Biomedical Sciences, University of Yaoundé 1, Yaoundé, Cameroon.

Received: 23 March 2018 Accepted: 13 January 2020

Published online: 21 January 2020

\section{References}

1. Young SB, Rose PG, Reuter KL. Vaginal fibromyomata: two cases with preoperative assessment, resection, and reconstruction. Obstet Gynecol. 1991;78(5 Pt 2):972-4.

2. Costantini E, Cochetti G, Porena M. Vaginal Para-urethral myxoid leiomyoma: case report and review of the literature. Int Urogynecology J. 2008;19:11835.

3. Chakrabarti I, De A, Pati S. Vaginal leiomyoma. J -Life Health. 2011;2:42-3.

4. Sim $\mathrm{CH}$, Lee JH, Kwak JS, Song SH. Necrotizing ruptured vaginal leiomyoma mimicking a malignant neoplasm. Obstet Gynecol Sci. 2014;57:560-3.

5. Wu Y, Wang W, Sheng $X$, Kong L, Qi J. A misdiagnosed vaginal leiomyoma: case report. Urol Case Rep. 2015;3:82-3.

6. Khan AT, Shehmar M, Gupta JK. Uterine fibroids: current perspectives. Int J Women's Health. 2014;6:95-114.

7. Vilos GA, Allaire C, Laberge P-Y, Leyland N, Vilos AG, Murji A, et al. The management of uterine leiomyomas. J Obstet Gynaecol Can. 2015;37:15778.

8. Laughlin SK, Stewart EA. Uterine leiomyomas: individualizing the approach to a heterogeneous condition. Obstet Gynecol. 2011;117(2 Pt 1):396.

9. Shimada K, Ohashi I, Shibuya H, Tanabe F, Akashi T. MR imaging of an atypical vaginal leiomyoma. Am J Roentgenol. 2002;178:752-4.

10. Asnani M, Srivastava K, Gupta HP, Kunwar S, Srivastava AN. A rare case of giant vaginal fibromyoma. Intractable Rare Dis Res. 2016;5:44-6.

11. Babacan A, Kizilaslan C, Gun I, Muhcu M, Mungen E, Atay V. CA 125 and other tumor markers in uterine leiomyomas and their association with lesion characteristics. Int J Clin Exp Med. 2014;7:1078-83.

12. Song K, Yu X, Lv T, Chen Y, Diao Y, Liu S, et al. Expression and prognostic value of lactate dehydrogenase-A and -D subunits in human uterine myoma and uterine sarcoma. Medicine (Baltimore). 2018;97. https://doi.org/ 10.1097/MD.0000000000010268.

13. Mollo A, Raffone A, Travaglino A, Di Cello A, Saccone G, Zullo F, et al. Increased $\mathrm{LDH} 5 / \mathrm{LDH} 1$ ratio in preoperative diagnosis of uterine sarcoma with inconclusive MRI and LDH total activity but suggestive CT scan: a case report. BMC Womens Health. 2018;18. https://doi.org/10.1186/s12905-0180662-5.

14. Shadbolt CL, Coakley FV, Qayyum A, Donat SM. MRI of vaginal leiomyomas. J Comput Assist Tomogr. 2001;25:355-7.

15. Sherer DM, Cheung W, Gorelick C, Lee Y-C, Serur E, Zinn HL, et al. Sonographic and magnetic resonance imaging findings of an isolated vaginal leiomyoma. J Ultrasound Med Off J Am Inst Ultrasound Med. 2007; 26:1453.

16. Chin H, Ong XH, Yam PKL, Chern BSM. Extrauterine fibroids: a diagnostic challenge and a long-term battle. Case Rep. 2014;2014:bcr2014204928.

17. Brady A, Laoide RÓ, McCarthy P, McDermott R. Discrepancy and error in radiology: concepts, causes and consequences. Ulster Med J. 2012;81:3.

18. Berlin L. Radiologic errors and malpractice: a blurry distinction. Am J Roentgenol. 2007;189:517-22.

19. Pinto A, Brunese L. Spectrum of diagnostic errors in radiology. World J Radiol. 2010;2:377 
20. Pinto A, Pinto F, Faggian A, Rubini G, Caranci F, Macarini L, et al. Sources of error in emergency ultrasonography. Crit Ultrasound J. 2013;5:S1.

21. Yarandi F, Eftekhar Z, Izadi-Mood N, Shojaei H. Accuracy of intraoperative frozen section in the diagnosis of ovarian tumors. Aust N Z J Obstet Gynaecol. 2008;48:438-41.

22. Sheyn I, Mira JL, Blanco R, Walton MB, Husseinzadeh N. Concomitant welldifferentiated adenocarcinoma and leiomyosarcoma of the uterus. Arch Pathol Lab Med. 2000;124:1539-41.

23. Wehbe GS, Doughane M, Bitar R, Sleiman Z. Laparoscopic posterior Colpotomy for a Cervico-vaginal leiomyoma: hymen conservative technique. Facts Views Vis ObGyn. 2016;8:169.

24. Egbe TO, Egbe TO. Prevalence and Outcome of Hysterectomy at the Douala General Hospital, Cameroon: A Cross-Sectional Study. Doi: https://doi.org/10. 23937/2378-3397/1410092.

25. Hawkins Y, Ussher J, Gilbert E, Perz J, Sandoval M, Sundquist K. Changes in sexuality and intimacy after the diagnosis and treatment of cancer: the experience of partners in a sexual relationship with a person with cancer. Cancer Nurs. 2009;32:271-80.

\section{Publisher's Note}

Springer Nature remains neutral with regard to jurisdictional claims in published maps and institutional affiliations.

Ready to submit your research? Choose BMC and benefit from:

- fast, convenient online submission

- thorough peer review by experienced researchers in your field

- rapid publication on acceptance

- support for research data, including large and complex data types

- gold Open Access which fosters wider collaboration and increased citations

- maximum visibility for your research: over $100 \mathrm{M}$ website views per year

At BMC, research is always in progress.

Learn more biomedcentral.com/submissions 